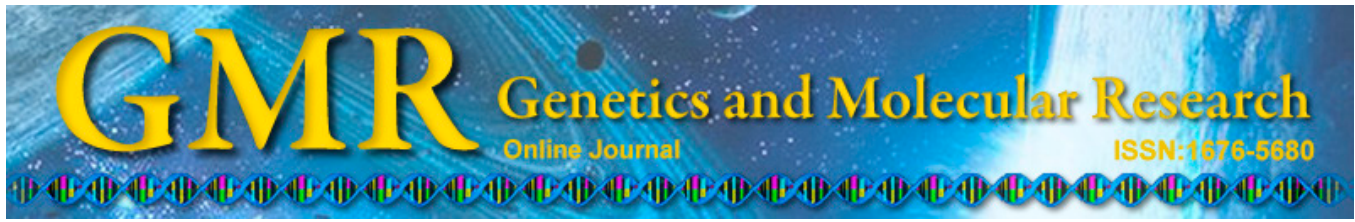

\title{
Rapid development of polymorphic microsatellite markers for the Amur sturgeon (Acipenser schrenckii) using next-generation sequencing technology
}

\author{
L.M. Li ${ }^{1,2,3}$, L. Wei ${ }^{4}$, H.Y. Jiang ${ }^{1,2,3}$, Y. Zhang ${ }^{5}$, X.J. Zhang ${ }^{1,2,3}$, L.H. Yuan ${ }^{1,2,3}$ \\ and J.P. Chen ${ }^{1,2,3}$ \\ ${ }^{1}$ Guangdong Entomological Institute, Guangzhou, China \\ ${ }^{2}$ Guangdong Public Laboratory of Wild Animal Conservation and Utilization, \\ Guangzhou, China \\ ${ }^{3}$ Guangdong Key Laboratory of Integrated Pest Management in Agriculture, \\ Guangzhou, China \\ ${ }^{4}$ College of Ecology, Lishui University, Lishui, China \\ ${ }^{5}$ College of Animal Science of Inner Mongolia Agriculture University, \\ Hohhot, China \\ Corresponding author: J.P. Chen \\ E-mail: chenjp@gdei.gd.cn
}

Genet. Mol. Res. 14 (3): 7910-7913 (2015)

Received November 24, 2014

Accepted May 11, 2015

Published July 14, 2015

DOI http://dx.doi.org/10.4238/2015.July.14.16

\begin{abstract}
Anthropogenic activities have seriously impacted wild resources of the Amur sturgeon, Acipenser schrenckii, and more information on local and regional population genetic structure is required to aid the conservation of this species. In this study, we report the development of 12 novel polymorphic microsatellite loci using next-generation sequencing technology, and the genotyping of 24 individuals collected from a sturgeon farm. The results show that the mean number of observed alleles per locus is 6.6 (ranging from 2 to 17). Observed and expected heterozygosity values ranged from 0 to 0.958 and from 0.508 to 0.940 , respectively. Not a single locus showed significant departure
\end{abstract}


from Hardy-Weinberg equilibrium and no linkage disequilibrium was observed among any pairwise loci. These highly informative microsatellite markers will be useful for genetic diversity and population structure analyses of $A$. schrenckii and other species of this genus.

Key words: Microsatellite; Polymorphism; Genetic diversity; Acipenser schrenckii; Next-generation sequencing

\section{INTRODUCTION}

Amur sturgeon (Acipenser schrenckii) is one of the most ancient fish in the world. In recent decades, anthropogenic impacts, such as water pollution, overfishing, and habitat deterioration, have caused widespread population declines of wild resources (Shmigirilov et al., 2007), and this species was listed in the Appendices to CITES at the 10th meeting of the Conference of the Parties in 1997 (Zhang et al., 2013a). However, artificial rearing of A. schrenckii is rapidly developing due to its high commercial value. A previous study of $A$. schrenckii mainly centered on its cultivation, breeding, and reproductive traits (Zhang et al., 2013b). The population genetic diversity and genetic structure of the species has also been investigated using the mitochondrial DNA cytochrome oxidase subunit I and microsatellite DNA markers (Zhang et al., 2013a). However, lack of sufficient polymorphic molecular markers has limited development of molecular phylogeny, population structure, and molecule-assisted selective breeding in this species. Therefore, isolation and development of additional novel polymorphic microsatellite or other molecular markers are necessary for analyzing genetic information in A. schrenckii. In this study, we isolated and developed polymorphic microsatellite loci for A. schrenckii using next-generation sequencing technology.

\section{MATERIAL AND METHODS}

Total RNA was extracted from liver tissue of $A$. schrenckii using Trizol (Invitrogen, USA), following the manufacturer protocol. Then, the cDNA library was constructed and sequenced using high-throughput Illumina sequencing technology. Simple sequence repeat (SSR) reads were identified from assembled sequences using the SSR Hunter software (Version 1.3) (Li and Wan, 2005). Primer pairs for selected microsatellites were designed using the Primer 5.0 software (Premier Biosoft International, USA). Genomic DNA of eight individuals of $A$. schrenckii was used to optimize amplification conditions and to screen for polymorphic SSRs.

To test the level of genetic polymorphism for these loci, fin tissue from 24 individuals of A. schrenckii from the Engineering and Technology Center of Sturgeon Breeding and Cultivation of the Chinese Academy of Fishery Science (Beijing, China) were sampled. Genomic DNA was extracted using the DNeasy Tissue Kit (Qiagen, Germany). PCR amplifications were performed in a $15-\mu \mathrm{L}$ reaction volume containing approximately $1 \mu \mathrm{L}$ template DNA, $1 \mu \mathrm{L}$ of each primer, 4.5 $\mu \mathrm{L} \mathrm{H}_{2} \mathrm{O}$, and $7.5 \mu \mathrm{L}$ premix Taq DNA polymerase (Takara, Japan). The amplification conditions were as follows: $95^{\circ} \mathrm{C}$ for $5 \mathrm{~min}, 35$ cycles at $94^{\circ} \mathrm{C}$ for $35 \mathrm{~s}$, annealing temperature (Table 1) for 35 $\mathrm{s}, 72^{\circ} \mathrm{C}$ for $40 \mathrm{~s}$, and a final extension at $72^{\circ} \mathrm{C}$ for $10 \mathrm{~min}$, ending with a $4^{\circ} \mathrm{C}$ hold. Electrophoresis was conducted on non-denaturing $10 \%$ polyacrylamide gels $(100 \mathrm{~V}, 12 \mathrm{~h})$ with a 50-bp ladder molecular maker (Tiangen, China) and a known allele size sample as a control, and gels were visualized using silver staining. Allele sizes were analyzed and digitalized by Gelpro 3.2. Observed 
heterozygosity, expected heterozygosity, and tests for deviations from Hardy-Weinberg equilibrium (HWE) and linkage disequilibrium (LD) were performed using the GENEPOP 4.0 software (Rousset, 2008) and FSTAT 2.9.3.2 for windows (Goudet, 1995), respectively.

\section{RESULTS}

Using the Illumina transcriptome sequencing method, a total of 50,142,328 clean reads and 214.3 Mbp were obtained from A. schrenckii cDNA (GenBank accession No. SRR1131121), which were assembled into 203,507 contigs with a mean length of $1053 \mathrm{bp}$. Of these contigs, 40,048 (19.7\% of all contigs) were identified that contained microsatellite loci, but only 24,135 contigs ( $60.3 \%$ of all microsatellite-containing contigs) contained potentially amplifiable loci. Within the 24,135 contigs, dinucleotides were the most dominant [18,174 $(75.3 \%)]$. The longest motif class (hexanucleotides) was present at very low frequency [5 $(0.02 \%)]$ and the numbers of the other motif classes were 5,612 (23.3\%), $327(1.35 \%)$, and $17(0.07 \%)$ for trinucleotides, tetranucleotides, and pentanucleotides, respectively. From these potential microsatellite locus contigs, 27 (6, 11, and 10 contigs of dinucleotides, trinucleotides, and tetranucleotides, respectively) were selected for primer design. Of the 27 potential microsatellite markers, 8 pairs were not easily amplified, 7 pairs were monomorphic, and the remaining 12 pairs of primers were polymorphic in the 24 individuals of $A$. schrenckii (Table 1). The observed numbers of alleles per locus ranged from 2 to 17 (mean 6.6). Observed heterozygosity ranged from 0 to 0.958 and expected heterozygosity ranged from 0.508 to 0.940 (Table 1). However, of the 12 microsatellite loci, 2 marker pairs (AS1266 and AS2189) showed homozygotes with more than 2 alleles. No one locus deviated significantly from HWE after Bonferroni's correction and no significant LD was observed in pairwise loci (Table 1).

\begin{tabular}{|c|c|c|c|c|c|c|c|c|}
\hline Locus & Primer sequence $\left(5^{\prime}-3^{\prime}\right)$ & $\begin{array}{c}\text { GenBank } \\
\text { accession No. }\end{array}$ & $\begin{array}{c}\text { Repeat } \\
\text { motif }\end{array}$ & $\mathrm{Ta}\left({ }^{\circ} \mathrm{C}\right)$ & $N_{\mathrm{A}}$ & $\begin{array}{c}\text { Size } \\
\operatorname{rang}(b p)\end{array}$ & $H_{\mathrm{O}} / H_{\mathrm{E}}$ & $\mathrm{P}$ \\
\hline AS352 & $\begin{array}{l}\text { F: AATGTCGTCCCATCTCAA } \\
\text { R: ATCATACCTCGTCTCACC }\end{array}$ & KJ623720 & $(\mathrm{GT})_{6}$ & 53 & 9 & $213-237$ & $0.250 / 0.770$ & 1.000 \\
\hline AS426 & $\begin{array}{l}\text { F: AACCGACGGCTATGTAAT } \\
\text { R: TTCCTTCTCACGCTGTAT }\end{array}$ & KJ623721 & $(\mathrm{GT})_{7}$ & 53 & 6 & $293-303$ & $0.125 / 0.653$ & 1.000 \\
\hline AS633 & $\begin{array}{l}\text { F: CCTGAACGGGAACCAAGT } \\
\text { R: AGGACACCTCACAGCACC }\end{array}$ & KJ623722 & $(\mathrm{GT})_{6}$ & 57 & 17 & $286-328$ & $0.583 / 0.940$ & 1.000 \\
\hline AS1266 & $\begin{array}{l}\text { F: GCAGATTGATAACCACCAG } \\
\text { R: TTTGAATAAAGCGGAAGC }\end{array}$ & KJ623723 & $(\mathrm{AC})_{6}$ & 53 & 2 & 181-183 & $0.000 / 0.508$ & 1.000 \\
\hline AS2189 & $\begin{array}{l}\text { F: GGCACTTTGTTAGGATTG } \\
\text { R: AAGACAGAGCCATTGAGG }\end{array}$ & KJ623724 & $(\mathrm{TA})_{5}$ & 53 & 3 & 303-307 & $0.000 / 0.524$ & 0.608 \\
\hline AS2725 & $\begin{array}{l}\text { F: CTGTCCGTTTATCCGTCC } \\
\text { R: CCTCTGCTGCCAACTCAA }\end{array}$ & KJ623725 & $(\mathrm{CA})_{6}$ & 57 & 5 & $161-185$ & $0.130 / 0.557$ & 1.000 \\
\hline AS3148 & $\begin{array}{l}\text { F: GCCTGGTGTTCACCTACCC } \\
\text { R: ATCCATTCGTCCACTCATTCT }\end{array}$ & KJ623728 & $(\mathrm{GCA})_{5}$ & 53 & 5 & $263-281$ & $0.167 / 0.660$ & 1.000 \\
\hline AS6682 & $\begin{array}{l}\text { F: CGCCTGGATTCTGTGAGT } \\
\text { R: AGAGTGTTGAGGTCGTAC }\end{array}$ & KJ623729 & $(\mathrm{TAT})_{5}$ & 53 & 5 & 184-208 & $0.042 / 0.660$ & 1.000 \\
\hline AS10282 & $\begin{array}{l}\text { F: AAATCTGCTTTGGGACACCC } \\
\text { R: CCGCTGACAACCAGTCTGAG }\end{array}$ & KJ623727 & $(\mathrm{TGTT})_{5}$ & 55 & 5 & $227-247$ & $0.739 / 0.741$ & 1.000 \\
\hline AS13185 & $\begin{array}{l}\text { F: CGAGTTGCCCAAGTCATT } \\
\text { R: GCGTCTCGCATCCATTTA }\end{array}$ & KJ623730 & $(\mathrm{CAT})_{6}$ & 54 & 10 & $189-216$ & $0.958 / 0.899$ & 1.000 \\
\hline AS16977 & $\begin{array}{l}\text { F: ATCCACGTATCCTTGCTT } \\
\text { R: AGTGCATGTGCCTTGTG }\end{array}$ & KJ623726 & $(\mathrm{CAGA})_{5}$ & 55 & 4 & $250-258$ & $0.167 / 0.712$ & 1.000 \\
\hline AS74678 & $\begin{array}{l}\text { F: TTGGCCCATTTATGCTTGTC } \\
\text { R: GGACAAAATCAGGGGCATCA }\end{array}$ & KJ623726 & $(\mathrm{CAGA})_{5}$ & 55 & 4 & $250-258$ & $0.167 / 0.712$ & 1.000 \\
\hline
\end{tabular}

Ta, annealing temperature of primer pairs; $N_{\mathrm{A}}$, number of alleles; $H_{\mathrm{O}}$, observed heterozygosity; $H_{\mathrm{E}}$, expected heterozygosity. 


\section{DISCUSSION}

This study was the first report on microsatellite loci development in A. schrenckii based on transcriptome using the next-generation sequencing technology (Illumina transcriptome sequencing method). Although relatively high proportion of monomorphic and not easy amplified loci were found, we have successfully detected and designed enough polymorphic microsatellite loci. Compared to traditional library-based approach such as magnetic bead enrichment (Hua et al., 2014), we could isolated and developed polymorphic microsatellite loci more faster and cheaper. This result is in agreement with recent studies (Perry and Rowe, 2011; Castoe et al., 2012; Nowak et al., 2014). Therefore, we could predict that the nextgeneration sequencing technology brings us powerful molecular tools for population genetic investigation in non-model organism.

\section{Conflicts of interest}

The authors declare no conflict of interest.

\section{ACKNOWLEDGMENTS}

Research supported by the Field Experimental Station Fund from Guangdong Academy of Sciences, China (\#sytz 201203) and the Innovation Talent Fund of Guangdong Entomological Institute, China (\#GDEI-cxrc2013).

\section{REFERENCES}

Castoe TA, Streicher JW, Meik JM, Ingrasci MJ, et al. (2012). Thousands of microsatellite loci from the venomous coralsnake Micrurus fulvius and variability of select loci across populations and related species. Mol. Ecol. Resour. doi: 10.1111/1755-0998.12000.

Goudet J (1995). FSTAT (version 1.2): A computer program to calculate F-statistics. J. Hered. 86: 485-486.

Hua LS, Wang FM, Gong SP, Ge Y, et al. (2014). Isolation and characterization of 14 polymorphic microsatellite loci in the big-headed turtle (Platysternon megacephalum). Biochem Genet. 52: 203-208.

Li Q and Wan JM (2005). SSRHunter: development of a local searching software for SSR sites. Hereditas 27: 808-810.

Nowak C, Zuther S, Leontyev SV and Geismar J (2014). Rapid development of microsatellite markers for the critically endangered Saiga (Saiga tatarica) using Illumina Miseq next generation sequencing technology. Conservat. Genet. Resour. 6: 159-162.

Perry JC and Rowe L (2011). Rapid microsatellite development for water striders by next-generation sequencing. $J$. Hered. 102: 125-129.

Rousset F (2008). Genepop'007: a complete re-implementation of the genepop software for Windows and Linux. Mol. Ecol. Resour. 8: 103-106.

Shmigirilov AP, Mednikova AA and Israel AJ (2007). Comparison of biology of the Sakhalin sturgeon, Amur sturgeon, and Kaluga from the Amur River, Sea of Okhotsk, and Sea of Japan biogeographic Province. Environ. Biol. Fishes 79: 383-395.

Zhang XM, Wu WH, Li LM, Ma XF, et al. (2013a). Genetic variation and relationships of seven sturgeon species and ten interspecific hybrids. Genet. Sel. Evol. 45: 21-30.

Zhang XM, Ma XF, Wu WH, Li LM, et al. (2013b). Polyploidy of Huso dauricus as revealed by microsatellite genetic markers. Chn. J. Zool. 48: 507-512. (In Chinese). 